\title{
10 Abkürzungen
}

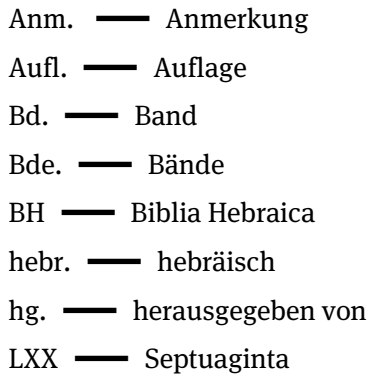

\section{Midraschim}

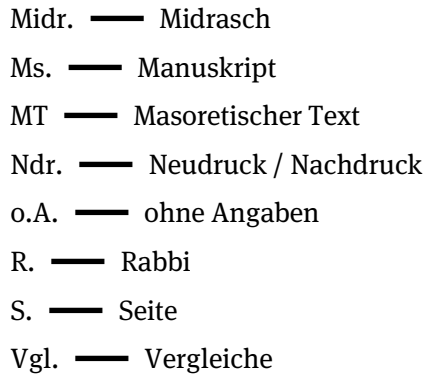

Ndr. — Neudruck / Nachdruck

R. - Rabbi

Vgl. — Vergleiche

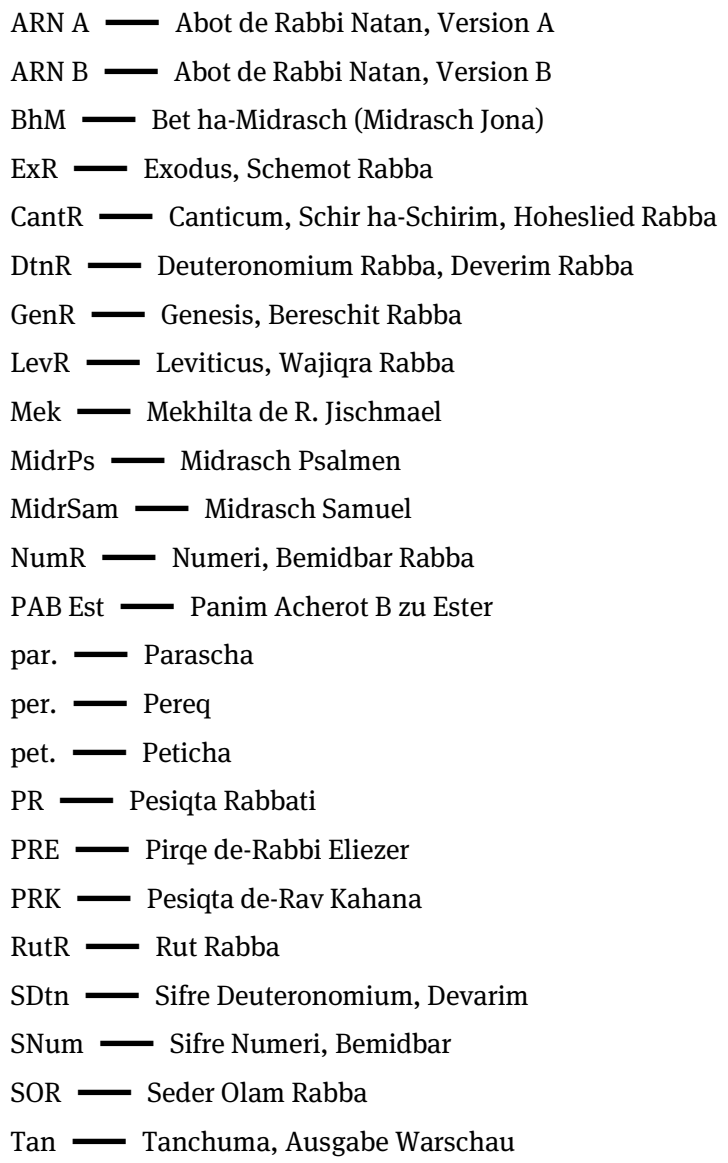


TanB — Tanchuma, Ausgabe Buber

ThrR — Threni, Klagelied, Echa Rabba

\section{Traktatnamen von Mischna, Tosefta, Talmudim}

b — Babylonischer Talmud

$\mathrm{t}$ - Tosefta

$\mathrm{j}-$ Jerusalemer Talmud

$\mathrm{AZ} \longrightarrow$ Aboda Zara

BB — Baba Batra

Bek - Bekhorot

Ber $\longrightarrow$ Berakhot

$\mathrm{BM} \longrightarrow$ Baba Metsia

BQ - Baba Qamma

Chag - Chagiga

Chul Chulin

Er $\longrightarrow$ Erubin

Git - Gittin

Jeb Jebamot

Ker - Keritot

Ket - Ketubbot

Mak Makkot
Meg - Megilla

Men - Menachot

MQ Moet Qatan

$\mathrm{Naz} \longrightarrow$ Nazir

Ned Nedarim

Nid — Nidda

Pes Pessachim

Qid Qidduschin

$\mathrm{RH}$ Rosch ha-Schana

Sanh - Sanhedrin

Schab Schabbat

Schebu - Schebuot

Suk - Sukka

Taan Taanit

Zeb Zebachim 
